The Labore Journal of Economics

Special Edition (September 2007)

\title{
Increasing Global Competitiveness: A Case for the Pakistan Economy
}

\section{Shamyla Chaudry*}

\begin{abstract}
The issue of global competitiveness is critical for developing countries. This paper looks at the drivers that influence industrial competitiveness and provides a comparison of these drivers for Pakistan, India and China. The analysis shows that Pakistan lags behind China and India in most of the main components of the industrial competitiveness index. The analysis also presents a series of micro and macro level policy recommendations aimed at increasing Pakistan's industrial competitiveness.
\end{abstract}

\section{Introduction}

The aim of this paper is to explain global competitiveness and its implications for Pakistan. The paper examines international data on global competitiveness and tries to develop an analysis to help improve strategies for today. The paper's focus is on the empirical literature on competitiveness using different composite indices. These include the following:

1. United Nations Industrial Development Organizations; World Industrial Development report (2002-2003)

2. World Economic Forums Global Competitiveness Report (up to WEF 2005-2006)

The principal objective of this study is to analyze factors that affect productivity and hence competitiveness and also to identify areas where Pakistan can strengthen its competitiveness so as to contribute to the overall growth performance. In order to do such an analysis, comparisons have been made with Pakistan's neighbours, India and China, and their success in international standings has been evaluated. A question which probably

${ }^{*}$ Assistant Professor, The Lahore School of Economics, Lahore 
comes to everyone's mind is why India and China, which enjoy the same geographic region with Pakistan, are well ahead of Pakistan in all aspects of competitiveness.

\section{Global Competitiveness Today}

The theme of competitiveness has remained the same; that is lower domestic costs hence lower the prices of goods. But ways to achieve this have changed over the years: from a pricing approach, that is the end user approach, there has been a shift to a costing approach, that is, the firm micro-level approach.

Competitiveness can be defined as sustainable growth in productivity that benefits the average person. Today, competitiveness in a global economy should not be confused with abundance of natural resources or cheap labor or continued exchange rate depreciations or, for that matter, protectionist policies to support local industries. Though these bring short term advantages, they do not facilitate the making of a dynamic economy. Professor Porter's model for competitiveness is created by a stable macro economic, political, legal and social environment and also a continuous yet proactive stance to improve the micro economic environment in which local firms are taken to the forefront and strategies are developed to foster an environment for local competition.

A recent study in the Industrial Development Report attempts to explain the "drivers" that seem to influence a country's ability to influence competitive industrial performance (CIP). Skills measured by the level of tertiary enrollment in technical subjects, research and development (R\&D) which is financed by productive enterprises, foreign direct investment (FDI) which includes total FDI investment with no distinction between exportoriented or domestic-oriented flows in manufacturing, royalties and technical fees which include fees paid to imported technology, and lastly modern infrastructure (ICT) by the use of telephone mainlines, are the five "drivers."

\footnotetext{
- $\quad$ CIP Score $=27.017+0.277$ skills $+0.036 \mathrm{R} \& \mathrm{D}+0.009 \mathrm{ICT}+$ 0.021 royalties +0.008 FDI.
}

The equation shows the drivers that enhance the CIP- competitive industrial performance index (based on a data base of 51 countries for the year 2000). A $1 \%$ enhancement in skills, namely enrollment in technical subjects such as science, mathematics, computing, and engineering, will increase the CIP by 0.3 . Not all the drivers are significant. R\&D, FDI and 
royalties achieve consistent significance whereas skills and ICT fail to do so as skills are highly correlated with $R \& D$. What this confirms is that technological efforts are positively related to the CIP, which are the bases for industrial success. FDI driven production and the export of high tech products affects competitive industrial performance positively. Royalties and technical fees are also positively related with industrial performance.

Table-I

\begin{tabular}{lccccc}
\hline Country & Rank & CIP Index & \multicolumn{3}{c}{ Change in Rank for } \\
& $(\mathbf{2 0 0 0 )}$ & (2000) & $\mathbf{1 9 9 0 - 2 0 0 0}$ & $\mathbf{1 9 8 0 - 1 9 9 0}$ & $\mathbf{1 9 8 0 - 2 0 0 0}$ \\
\hline Pakistan & 49 & 0.235 & -2 & 6 & 4 \\
India & 40 & 0.275 & -4 & 2 & -2 \\
China & 24 & 0.379 & 2 & 3 & 15 \\
\hline
\end{tabular}

Source: UNIDO scoreboard of core sample database)

Starting with a CIP score of 0.192 (rank 53) in the 1980 s to 0.219 (rank 47) in the 1990s to 0.235 (rank 49) in the 2000s, Pakistan has lost ground mainly due to exogenous shocks, political instability, poor macro management, policy liberalization and an over reliance on primary products. China started off with a score of 0.240 (rank 39) in the 1980s to 0.323 (rank 26) in the 1990s to a score of 0.379 (rank 24) in the 2000s showing a sustained improvement in each decade as there have been rapid rises in manufactured exports and a significant upgrading of technological structure of exports. But again policy liberalization has slowed the process of improvement in China's global competitiveness. A number of studies conclude that China's growth would have been relatively higher had policy liberalization not been forced on China. India's performance amounted to a CIP score of .243 (rank 38 ) in the 1980 s to 0.262 ( $r a n k 36$ ) in the 1990 s to 0.275 ( $\operatorname{rank} 40$ ) in the 2000s showing that it has upgraded its technology structure from a relatively low level and has a medium share of manufactured goods with a low per capita export value. The reason for the stagnation of Indian competitiveness can be attributed to slow medium and high technology (MHT) sector growth in the1990s which was a result of policy liberalization in the form of increased advertising budgets at the cost of R\&D budgets. The small slip in the index also implies that the neighbouring country, namely China, has been doing better.

The World Economic Forum defines competitiveness as a set of factors, institutions and policies that underline the level of productivity; if one wants to increase productivity, hence competitiveness, one has to 
make better use of the available resources. The Global Competitiveness Index (GCI) incorporates nine factors that lead to increased productivity and competitiveness. The GCI incorporates the concept of stages of development, attaches different weights to different sub-indices and provides individual countries with a useful tool to identify the barriers to competitiveness. The pillars are divided into three broad categories, those being the basic requirements, efficiency enhancers and innovation and sophistication factors. These are then further sub-divided into the nine pillars, that is, institutions, infrastructure, macro economy, health and primary education, higher education and training, market efficiency (goods, labor, financial), technological readiness, business sophistication and innovation. Pakistan, India and China are classified as factor driven economies with a GDP per capita of less than $\$ 2000$. For such economies the basic requirement sub-index is the most important as it has the highest weight attached to it in constructing the GCI. Economies with GDP per capita ranging from $\$ 3000$ to $\$ 9000$ are classified as efficiency driven economies, whereas countries with GDP per capita greater than $\$ 17,000$ are classified as innovation driven economies. Naturally all three categories assign different weights to the three sub indices. Using the three weights the GCI has been constructed for Pakistan, India and China.

\section{Table-II}

\begin{tabular}{lcll}
\hline Weights & Pakistan & India & China \\
\hline Factor driven & 3.66 & 4.44 & 4.24 \\
Efficiency driven & 3.585 & 3.56 & 4.125 \\
Innovation driven & 3.594 & 4.461 & 4.029 \\
Equal weights & 3.629 & 4.47 & 4.067 \\
\hline
\end{tabular}

Source: GCI index 2005-2006)

Using different weights we can see that for all the countries the GCI score deteriorates as we move from factor driven weights to innovation driven weights and only in the case of equal weights, does India show a minor improvement of 0.03 where as Pakistan and China both lose ground. This contradicts the report on the state of Pakistan's competitiveness that asserted that by assigning equal weights to the sub-indices Pakistan's score could have been relatively higher.

Referring to the Table-III one can see a stark contrast between the three economies that have been classified as factor driven economies. Analysis has been provided for such differences. Under the first four pillars 
which make up the basic requirement category, except for infrastructure, health and education, Pakistan's ranking has fallen. The fifth, sixth and seventh pillars that fall under the efficiency enhancer's category have shown stagnation.

Considering the eighth and the ninth pillar that come under innovative factors, Pakistan has slid under the eighth pillar but has shown considerable improvement in the ninth pillar. Factor driven economies such as Pakistan define competition based on factor endowments such as unskilled labor and natural resources.

Today Pakistan lags behind in all the categories of the GCI index. Though the figures show an improvement in Pakistan's rank from 98th to 91st, this does not indicate any improvement but merely the fact that more countries have been included in the index. Health and education when compared to India (5.9) and China (6.44) are weak areas for Pakistan (4.79). Human capital development is the weakest in Pakistan as indicated by the higher education and training (fifth pillar). Pakistan is a low wage, labor surplus economy with low productivity. However, firm-level comparisons suggest that while wages in Pakistan are low by international standards, they are often significantly higher than those in the Sub-continent. Slow growth in private investment in the large scale manufacturing sector has dampened Pakistan's economic growth. Pakistan has liberalized trade but highly protected domestic markets have reduced the incentives to exports. Also high costs and poor functioning of infrastructure are considered to be harmful impediments for Pakistan's growth. 
Table-III: Global Competitiveness Indexes: Cross-Country Comparisons 2006 - 2007)

\begin{tabular}{lcccccc}
\hline & \multicolumn{2}{c}{ China } & \multicolumn{2}{c}{ India } & \multicolumn{2}{c}{ Pakistan } \\
& Rank & Score & Rank & Score & Rank & Score \\
\hline Basic Requirements & 44 & 4.8 & 60 & 4.51 & 93 & 3.96 \\
Institutions & 80 & 3.51 & 34 & 4.55 & 79 & 3.51 \\
Infrastructure & 60 & 3.54 & 62 & 3.50 & 67 & 3.36 \\
Macro economy & 6 & 5.72 & 88 & 4.12 & 86 & 4.19 \\
Health \& Primary Education & 55 & 6.44 & 93 & 5.90 & 108 & 4.79 \\
Efficiency Enhancers & 71 & 3.66 & 41 & 4.32 & 91 & 3.27 \\
Higher Education \& Training & 77 & 3.68 & 49 & 4.35 & 104 & 2.82 \\
Market efficiency (goods, labor, & 56 & 4.22 & 21 & 5.07 & 54 & 4.23 \\
financial) & 75 & 3.07 & 55 & 3.52 & 89 & 2.77 \\
Technological Readiness & & & & & & \\
Innovation \& Sophistication & 57 & 3.75 & 26 & 4.60 & 60 & 3.66 \\
Factors & 65 & 4.05 & 25 & 5.06 & 66 & 4.05 \\
Business Sophistication & 46 & 3.44 & 26 & 4.14 & 60 & 3.27 \\
Innovation & 54 & 4.24 & 43 & 4.44 & 91 & 3.66 \\
Overall Index & & & & & &
\end{tabular}

(Source: Global Competitiveness Report (2005-2006))

India ranked 43 rd overall with excellent scores in the capacity for innovation and sophistication of firm operations. Firm use of technology and rates of technology transfer are high, although penetration rates of the latest technologies are still quite low which reflects India's low levels of per capita income and high level of poverty. A lack of adequate health services and education as well as a poor infrastructure are limiting a more equitable distribution of the benefits of India's high growth rates. When comparing the infrastructure pillar, India and China have very close figures which is highly debatable. Indian governments have been ineffective in reducing the public sector deficit, which is one of the highest in the world, and that would seem to cause their rankings to slide in the macro economy pillar.

China's ranking has fallen form 48 to 54, characterized by heterogeneous performance. On the positive side, China's growth rates coupled with low inflation, one of the highest savings rate in the world, and hence investment and manageable levels of public debt have boosted China's ranking on the macro economy pillar of the GCI to 6th place. However, a number of structural weaknesses have arisen, including in the 
banking sector that is mainly controlled by the State. China has low penetration rates for the latest technologies (mobile telephones, internet, personal computers), and secondary and tertiary school enrolment rates are still relatively low. There has been a drop in the quality of the institutional environment, a slide in the rankings from 60 to 80 in 2006, with poor results across all 15 institutional indicators, spanning both public and private institutions. China has created a much more competitive environment than India or Pakistan considering the tax structure, infrastructure, capital costs and labor legislation. China is well known for the low costs of its workforce and its investment rate which is one of the highest in the world. China invests enormously in education, infrastructure and technology, yet people mistake China's competitiveness as a result of cheap labor and piracy. China's competition is felt particularly in some sectors requiring a great deal of manual labor such as footwear, textiles and small appliances. But in the next five years China's auto industry will pose to be a looming threat for other car manufacturing industries across the world. In China, local firms are gaining ground over foreign competitors. These companies are receiving a boost from government policies that require at lease $70 \%$ of new machines to be made at home in sectors such as energy. Such incentives are likely to increase its growth.

\section{Conclusion and Recommendations}

Pakistan started out a poor nation at independence with dependency on agriculture. The economy has seen ups and downs which have discouraged Pakistan's growth. In the 60s there was major investment in infrastructure, huge sugar mills and textile industries, and import substitution was implemented. It was at this time that Pakistan was considered to be an economic player of the Sub-continent. By the 70s political hurdles dissuaded Pakistan's progress and the nationalization of industry brought growth to a stand-still. In the next era of the military regime there was a heavy inflow of US aid and spending by the public sector was seen to be on the rise. The next decade, that is the $90 \mathrm{~s}$, can broadly be classified as a decade of lost opportunities with heavy borrowing both in the public and private sector that has resulted in being a burden on the economy today. Therefore, today prudence in economic management is crucial. But the trick that needs to be learned is to find means to support and accelerate rather than hinder enterprise development. For global competitiveness today is more reliant on the micro environment as opposed to the macro environment. A number of recommendations are being cited here with reference to the two neighbouring countries that have done better than Pakistan. 
Competitiveness today requires a strong base of human and technological resources. However, in Pakistan per capita R\&D spending is amongst the lowest. Among the high growth newly industrialized economies, there have been substantial national variances in the way exports were promoted. The challenge for Pakistani governments will be to provide support, not direction, for the private sector. Also Pakistan needs to establish alliances with countries that have technological capabilities in sectors operating at lower technological levels. The essence of competitiveness is to promote in-firm learning, skill development and technological effort and to coordinate the collective learning process. To compete, Pakistani enterprises must adopt new technologies and organizational methods and link themselves to the global value chain. Coping with new technologies calls for new skills, innovative production structures, improved infrastructure and institutions. Today, competitiveness will involve the upgrading of technologies in all activities building new capabilities and finding new markets and market niches. Pakistan needs to reevaluate its exports, and even with Pakistan's cotton resources and upgrading of textile facilities, will it remain a major player in textile and apparel market, where Pakistan has lost market share to countries like China, India, and recently to Bangladesh and Sri Lanka? In the long run export diversification is necessary. Pakistan's wage rates are comparable those of India and China but its export structure is biased towards low technology products. Therefore, Pakistan's scores are relatively low on export sophistication. That means that Pakistan specializes in the low value added section of the textile industry. Unfortunately, Pakistan is highly dependent on apparel products that are considered to be one of the most non dynamic exports; with sliding market shares and entry from other countries, that makes Pakistan's position vulnerable. It also faces competition from China and India who are investing heavily in new technology, designs and skills which may outperform Pakistan. Therefore specializing in textile and clothing is not recommended in the future. It needs to diversify into other sectors where it has a competitive edge. Should Pakistan switch its production from low tech goods to primary products? At this point we are not saying that Pakistan should never produce high tech products, but build on its capabilities to develop goods that provide value addition.

What should Pakistan do in the meantime? Recent examples of exports of various citrus fruit varieties, mangoes, flowers, dairy products and a number of other such products will provide the diversification needed to strengthen exports. Also a study conducted by the World Bank indicates the potential for more trade with India, especially light manufactured products such as bicycle components and fans. Pakistan has to reevaluate its stance on 
its medical instruments product categories, one of its most dynamic exports, where Pakistan has been losing its world market share.

With low ranks in the basic requirements sub-index, Pakistan has to improve at the macro level so that an environment can be fostered for the individual firm. Pakistan has to improve in areas of health and primary education and also improve the higher education and training pillar. The investment climate, coupled with the uncertain national and regional situation, has kept foreign direct investment (FDI) inflows less than those of China. For competitiveness today a country requires adequate infrastructure, cheap labor and liberal economic policies. Therefore Pakistan requires export diversification, firm level technological upgrading and the development of clusters.

However, why are some industries in Pakistan doing well despite a low competitive rating? Are these the results of some ingenious ways of doing business? Is the Pakistani entrepreneur really proactive? Further research needs to be directed in this area. The Business Competitiveness Index addresses firm level operations and the national business environment with relatively higher weights given to the latter. Pakistan's performance has improved over the years from 77th to 67th place where China stands at 57 th and India is currently at 31 st place. When these ranks are compared with other countries in the region, Pakistan has to strive hard to develop not only a strong national business environment, but also try to capture firm level ingenuity.

Certain high priority areas have been identified by a study conducted by the World Bank for accelerating Pakistan's growth and hence its global competitiveness. Some of these measures require quick decisions whereas others require long term efforts. The measures include:

- $\quad$ Strengthening the macroeconomic framework (long term)

- $\quad$ Analyzing electricity pricing and structural issues

- $\quad$ Improving SME's access to financing

- Serious commitment to human capital development and to increase the supply of skilled labor (long term)

- Improvements in the efficiency of the duty-drawback and sales tax rebates systems for new or small exporters and new exporting activities 
- Improvements in transport and trade logistics (long term)

- $\quad$ Enhancing food and safety standards 


\section{References}

ADB Institute-Pakistan Resident Mission Seminar Paper, 2004, "Industrial Competitiveness: The Challenge for Pakistan”, ADB Institute, Asian Development Bank.

Ansari. Javed A., 2005, "Pakistan's Industrial Competitiveness", College of management Science, PAF-Karachi Institute of Economics and Technology.

Aw, Bee Yan; Chung, Sukkyun and Roberts mark J., 2000, "Productivity and Turnover in the Export Market: Micro-Level Evidence from the Republic of Korea and Taiwan (China)", The World Bank Economic Review, Vol. 14, No. 1, pp. $65-90$.

Balduf, Artur; Carvens, David W. and Wagner, Udo, 2000, "Examining Determinants of Export Performance in Small Open Economies", Journal of World Business, Vol. 35, No. 1.

Britto, Jorge and Janeiro, Rio de Janeiro, "Industrial Competitiveness and Inter-Firm Co-operation: An Analysis of Stylized Models of Inter-Firm Networks".

“Global Competitiveness Report 2003 / 2004”, World Economic Forum.

“Global Competitiveness Report 2004 / 2005”, World Economic Forum.

“Global Competitiveness Report 2004 / 2006”, World Economic Forum.

“Global Competitiveness Report 2006 / 2007”, World Economic Forum.

Government of Pakistan, Finance Division; "Pakistan Economic Survey 2005 - 2006”.

Katsikeas, Constantine S. and Leonidou, Leonidas C., 1996, "Export Market Expansion Strategy: Differences Between Market Concentration and Market Spreading”, Journal of Marketing Management, Vo1. 12, pp. $113-134$.

Khan, Mehmood - U1- Hassan, "Exports in 2006: A Critical Review", Business \& Finance Review, the News International, Monday, January 8th 2007. 
Khan, Mehmood, Shazia; "Good Economic Indicators Pointing towards Sustainable Development”, Business and Finance Review, The News International, Monday, October 16th 2006.

Maske11, Peter and Malmberg, Anders, 1995, "Localized Learning and Industrial Competitiveness", Ministry of Finance, Government of Pakistan, and USAID.

Nazar, Yousaf; "Economy: Challenges Ahead", Economic and Business Review, the Dawn News, 1-7th January, 2007.

Omar, Kaleem, "The Ups and Downs of Pakistan's Economic Scenario: A Review" Business and Finance Review, The News International, Monday, January 8th 2007.

Ora1, Muhittin and Ozkan Alev O., Apr., 1986, “An Empirical Study on Measuring Industrial Competitiveness", The Journal of the Operational Research Society, Vo1. 37, No. 4, pp. 345-356.

Paulo, Sao; "barzils', China's Economies Compete”, Business and Finance Review, The Daily Times, Tuesday, April 3rd, 2007.

Porter, Michael, E.; ed, "Competition in Global Industries", Harvard Business School Press, Boston

“UNIDO Industrial Development Report 2002 - 2003”, United Nations Industrial Development Organization.

Wignaraja, Ganeshan and Joiner, David, 2004, "Measuring Competitiveness in the Worlds Smallest Economies: Introducing the SSMECI", Economic and Research Department Paper Series, N0.60.

World Bank Documents, 2006, "Pakistan Growth and Export Competitiveness”, Report No. 35499-PK, World Bank. 